\title{
Factor Structure and Measurement Invariance of the Perceived Social Support Scale in Women Diagnosed with Breast Cancer
}

Yaoxin Chen

Second Xiangya Hospital

Yan Han

Second Xiangya Hospital

Xiang Wang

Second Xiangya Hospital

Huan Zhou

Second Xiangya Hospital

Yao Liu

Second Xiangya Hospital

Lingyan Li

Nanchang University

Yuping Wang

Xi'an Jiaotong University School of Humanities and Social Sciences

Jie Fan

Second Xiangya Hospital

Tamini Soondrum

Second Xiangya Hospital

Xiongzhao ZHU ( $\nabla$ xiongzhaozhu@csu.edu.cn )

Second Xiangya Hospital https://orcid.org/0000-0002-7573-0740

\section{Research}

Keywords: Perceived Social Support, Breast cancer, Factor structure, Measurement invariance

Posted Date: March 2nd, 2021

DOI: https://doi.org/10.21203/rs.3.rs-254227/v1

License: (c) (i) This work is licensed under a Creative Commons Attribution 4.0 International License. Read Full License 


\section{Abstract}

Background: The perceived social support of breast cancer patients has a great effect on regulating their negative emotions such as anxiety and depression, which is helpful to improve their mental health level. The Perceived Social Support Scale (PSSS) is a frequently used instrument designed to assess the degree of perceived social support.

However, the psychometric properties of PSSS in breast cancer patients have not been adequately studied. The purposes of this study were to evaluate the factor structure of PSSS and examine its measurement invariance across different demographic variables in a sample of breast cancer patients.

Method: This study involved 989 female patients diagnosed with breast cancer, aged from 25 to 72 years old (Mean age $=47.67$ years, $S D=8.87$ ). The single-group confirmatory factor analysis was administrated to examine the factor structure of PSSS. The multi-group confirmatory factor analysis was used to demonstrate the measurement invariance of PSSS across different sociodemographic variables.

Results: The PSSS had satisfactory reliability and validity in current sample. The three-factor model fit well in the overall sample and population subgroups. Configural, metric, scalar, and strict invariances were all supported by the data of breast cancer samples across different age, places of residence and educational levels.

Conclusion: This study examined the factor structure and measurement invariance of PSSS across different demographic variables in women diagnosed with breast cancer. Our results proved that PSSS is suitable for use among breast cancer patients.

\section{Background}

Breast cancer is a disease of global concern due to its high incidence and rising mortality. According to the 2018 Global Cancer Statistics Report[1], the number of newly diagnosed breast cancer cases worldwide reached 2.1 million, accounting for about a quarter of the total number of new cases of female malignant tumors. Breast cancer is the most commonly diagnosed cancer in the vast majority of the countries and is becoming a leading cause of cancerborne death in women. The diagnosis and treatment of breast cancer will be psychologically strenuous and may lead to severe psychological distress to patients[2]. Due to adverse effects of breast cancer treatment, patients are often accompanied by negative emotions such as anxiety and depression[3]. Social support has played a vital role in the treatment of breast cancer patients. Studies have shown that breast cancer patients receive support from their spouses, family, friends and colleagues, which makes them feel loved and cherished, and can help to promote posttraumatic growth[4].

Social support can be divided into objective support and subjective support[5]. Objective support refers to visible, and practical support, including direct material assistance and the existence as well as the participation of group relations[6]. Subjective support is also known as perceived social support, which stems from an in-depth research on social support, and which reflects the emotional experience and evaluation of the degree of external support[6]. In the last few decades, several qualitative and quantitative scales were developed to measure social support. The Perceived Social Support Scale (PSSS) was one of the most extensively used scale, which was developed by Zimet[7] et al to provide the quantitative measurement of individuals' perceptions of social support from family, friends and significant others. This scale had several advantages. With just 12 items, it was simple and easy to operate. Unlike other similar tools, it could also measure support in multiple areas. The Perceived Social Support Scale has been translated into multiple languages, such as: Chinese version[8]; French version[9]; Turkish version[10-13]; Portuguese version[14, 15]; Spanish version[16,17], etc. Many studies had shown that this scale exhibited excellent psychometric properties in 
different cultures and were widely used in different countries[18-21]. It can be applied not only to healthy people but also to various clinical patients such as diabetes[22], breast cancer, autism and mental disorders. In brief, the PSSS is an adaptable instrument for evaluating perceived social support in a variety of samples. Moreover, many scholars had explored the factor structure of the PSSS and confirmed the three-factor structure, named as support from family, friends and other aspects[9, 23-25]. There were a few scholars believed that the two-factor model can also be applicative, which divided the source of support into family support and other support sources[8, 26].

Perceived social support may help breast cancer patients to adjust their state of mind in the face of stressful life events. There have been numerous previous clinical studies on perceived social support for women with breast cancer[27-29]. To the best of our knowledge, no studies had been conducted to examine the factor structure and measurement invariance of the PSSS in women diagnosed with breast cancer.

Uncertain factor structure of research tools may lead to biased research results. Therefore, it is very necessary to confirm the factor structure of the PSSS in specific participants. With this in mind, one of our research purposes was to examine the most applicable factor model of the PSSS in Chinese women who were diagnosed with breast cancer.

In addition, according to previous studies, breast cancer patients with different sociodemographic variables were found to have different levels of reporting social support scores. For example, Kim and Jang[30] found that the level of perceived social support among breast cancer patients differed significantly in educational background.

Sammarco[31] demonstrated that younger breast cancer patients reported significantly more perceived social support than older ones. Another study showed that patients who lived in cities had significantly higher PSSS scores than those who lived in rural areas[32]. However, if we want to prove that these comparative results are reliable, we need to prove the measurement invariance of the PSSS in the patients diagnosed with breast cancer. In other words, invariance is a prerequisite for the comparison of differences between different groups. As far as we know, there are currently no research that can be used as evidence of the measurement invariance of PSSS in different sociodemographic variable groups of breast cancer patients. It prompted us to do more research in this study to evaluate the measurement invariance of the PSSS in a sample of breast cancer patients across different demographic variables (age, places of residence and educational levels).

In all, the purposes of this work were to: (1) evaluate the construct validity of PSSS in women diagnosed with breast cancer; (2) test the factorial invariance of PSSS using a range of demographic variables (age, places of residence and educational levels).

\section{Methods}

\subsection{Participants}

During the period from March 2011 to March 2016, we recruited 1030 female patients who had been diagnosed with breast cancer from two hospitals in Hunan Province of Mainland China to participate in this study. Patients with a known history of major psychiatric disorder or substance abuse were excluded. All the data had been checked. Of 1030 patients who agreed to take part in the study, 11 (1.1\%) patients were excluded due to data missing on most items of the PSSS. In addition, 13 (1.3\%) patients did not report their ages, 17 (1.7\%) patients did not report years of schooling, and were thus eliminated. The final analytic sample consisted of 989 female patients with breast cancer.

All patients participating in this study were well informed of the content and confidentiality policy. All participants voluntarily signed an informed consent form.

\subsection{Instruments}


The Chinese version of the Perceived Social Support Scale (PSSS) was used in this study. It was used to evaluate the degree of support from various social support sources that an individual felt and understood. The PSSS contained 12 items reflecting three sources of support (family, friends and significant others). The scale was scored on a sevenpoint Likert-type scale that ranged from 1 (very strongly disagree) to 7 (very strongly agree). The higher the score of each dimension and the total table, the higher will be the degree of social support that the individual understood. In this study, Cronbach's alpha of the whole scale was 0.95 , showing high internal consistency.

\subsection{Procedure}

The study was carried out in hospital wards. Participants received a copy of the printed questionnaire immediately after providing informed consent. All participants were requested to fill up the self-report questionnaire on the spot. There was an experienced psychology student nearby who could provide professional assistance if they had some questions about the questionnaire.

\subsection{Data analysis}

SPSS version 22.0 and Mplus version 7.0 were used to calculate descriptive statistics and conduct item analyses in this study[33].

Firstly, in order to determine the optimal factor structure of the PSSS in the breast cancer population, single-group confirmatory factor analysis (CFA) was administrated to verify the three-factor model and two-factor model of PSSS. At the same time, we can evaluate the construct validity of the scale. Considering the non-normality of the data, all the measurement models were estimated using the maximum likelihood estimation with standard error and meanvariance corrected chi-square test statistics (MLMV)[34]. Because of the sensitivity of the chi-square $\left(\chi^{2}\right)$ test statistic to sample size[35], the following goodness-of-fit indexes were used to evaluate the adequacy of the model fit to the data, including the chi-square/degree of freedom $\left(\chi^{2} / \mathrm{df}\right)$, the comparative fit index (CFI), the Tucker-Lewis index (TLI), the Bayesian information criterion (BIC), standardized root mean square residual (SRMR), and root mean square error of approximation (RMSEA) with a $90 \%$ confidence interval (CI). Generally, CFI $\geq 0.90, \mathrm{TLI} \geq 0.90, \mathrm{SRMR} \leq 0.08$ and RMSEA $\leq 0.08$ can indicate an acceptable model fit[36]. The model with larger CFI and TLI as well as smaller RMSEA and $\mathrm{BIC}$ values was the most appropriate.

Secondly, the multigroup confirmatory factor analysis method was applied to test the measurement invariance of PSSS across age (younger and older), levels of education (lower and higher), and places of residence (rural and urban). A series of hierarchically nested models were tested, including configural, metric, scalar, and strict invariance models[37]. Every model represented a specific level of measurement invariance, ranging from minimum invariance to maximum invariance. There is a progressive nesting relationship between different levels of invariance. Configural invariance (Model 1) was used to determine whether the factor structure fitted each group in the same manner. It was an initial analysis with no constraints, with the factor loadings, intercepts of variables and error variances being set free. Metric invariance (Model 2) was used to gauge whether factor loadings were similar in both groups. In this model, the constraints of equivalent factor loadings were imposed, and the intercepts of variables and error variances were freely estimated. Scalar invariance (Model 3) was used to assess whether factor loadings and intercepts were similar in both groups. The factor loadings and intercepts of variables were constrained to be equal across age, levels of education, and places of residence. Strict invariance (Model 4) was used to test whether factor loadings, intercepts and the error variances between different groups were similar. The factor loadings, intercepts of variables and error variances were all set to be equal across age, levels of education, and places of residence. Posterior models were nested on the former one. Only when the former model was set up, the next model was allowed to be done. 
In order to evaluate invariance between consecutive models, the $\triangle \mathrm{CFI}$ and $\triangle \mathrm{RMSEA}$ were examined. $\mathrm{A} \triangle \mathrm{CFI}$ value of less than 0.01, a $\triangle$ RMSEA value of less than 0.01 and a smaller BIC value were considered to be evidence of invariance[35], given that the values have been widely used and supported in recent researches[38, 39].

\section{Results}

\subsection{Descriptive Statistics}

A total of 989 female patients diagnosed with breast cancer participated in the study. The age of these participants ranged from 25 to 72 years old (Mean age $=47.67$ years, SD $=8.87$ ). The vast majority of participants $(93.5 \%)$ were married women. A few patients are divorced (3.3\%), or widowed (2.8\%), or single $(0.3 \%)$. The years of education of these participants ranged from 0 to 19 years (Mean year $=10.12$ years, SD $=3.57$ ). The patients from urban and rural areas each accounted for about half of the sample size. All patients participating in the questionnaire were receiving breast cancer treatment. $23.5 \%$ of patients were receiving chemotherapy before mastectomy; $70.9 \%$ of patients had just finished mastectomy and were undergoing chemotherapy; $5.6 \%$ of patients were receiving rehabilitation after mastectomy. The detailed basic information of the patient was presented in Table 1. The descriptive data of the scale scores were shown in Table 2. 
Table 1

Demographic and disease related

information of the patients

\begin{tabular}{|ll|}
\hline Item & N (\%) \\
\hline Years of age & \\
\hline$\leq 45$ & $445(45.0 \%)$ \\
\hline$>45$ & $544(55.0 \%)$ \\
\hline Marital status & \\
\hline Married & $925(93.5 \%)$ \\
\hline Divorced & $33(3.3 \%)$ \\
\hline Widowed & $28(2.8 \%)$ \\
\hline Single & $3(0.3 \%)$ \\
\hline Educational level & \\
\hline$\leq 9$ years & $570(57.6 \%)$ \\
\hline$>9$ years & $419(42.4 \%)$ \\
\hline Place of residence & \\
\hline Urban & $534(54.0 \%)$ \\
\hline Rural & $455(46.0 \%)$ \\
\hline Stage of disease & \\
\hline Preoperative & $233(23.5 \%)$ \\
\hline Postoperative & $701(70.9 \%)$ \\
\hline Convalescent & $55(5.6 \%)$ \\
\hline
\end{tabular}


Table 2

Descriptive data on items scores.

\begin{tabular}{|lllll|}
\hline Item & Mean & SD & Skewness & Kurtosis \\
\hline 1 & 5.73 & 0.956 & -1.115 & 2.104 \\
\hline 2 & 5.42 & 1.074 & -0.845 & .803 \\
\hline 3 & 6.25 & 0.756 & -1.278 & 3.891 \\
\hline 4 & 6.21 & 0.823 & -1.237 & 2.859 \\
\hline 5 & 5.19 & 1.158 & -0.459 & -0.243 \\
\hline 6 & 5.17 & 1.253 & -0.685 & 0.262 \\
\hline 7 & 5.12 & 1.321 & -0.663 & 0.113 \\
\hline 8 & 5.95 & 0.939 & -0.953 & 1.363 \\
\hline 9 & 5.25 & 1.273 & -0.841 & 0.482 \\
\hline 10 & 5.45 & 1.034 & -0.595 & 0.472 \\
\hline 11 & 6.23 & 0.779 & -1.027 & 1.742 \\
\hline 12 & 5.28 & 1.346 & -0.852 & 0.305 \\
\hline
\end{tabular}

\subsection{Single Group Confirmatory Factor Analyses}

Firstly, the data fitting of the three-factor model and two-factor model were tested in the total sample. The fit indices of the two factor structure models in the total sample were listed in Table 3. The fit indices of the three-factor model were as follows: $\chi 2=345.385(\mathrm{df}=51 ; p<0.001) ; \mathrm{CFI}=0.960 ; \mathrm{TLI}=0.949 ; \mathrm{SRMR}=0.035 ; \mathrm{RMSEA}=0.076(90 \% \mathrm{Cl}$ : 0.069 , 0.084 ) and $\mathrm{BIC}=22690.662$. All parameters met the fitting requirements. It could be seen that the three-factor model showed tight fitting to data. The fit indices of the two-factor model were found as: $\chi 2=1128.897(\mathrm{df}=53 ; p<0.001)$; $\mathrm{CFI}=0.856 ; \mathrm{TLI}=0.820 ; \mathrm{SRMR}=0.086 ; \mathrm{RMSEA}=0.143(90 \% \mathrm{Cl}: 0.136,0.151)$ and $\mathrm{BIC}=23950.514$. In view of the fact that the CFI and TLI of the three-factor model were larger and the RMSEA and BIC were smaller, the three-factor model outperformed the two-factor model in the total sample. Furthermore, we conducted the CFAs for groups of different age, places of residence, and education levels. The fit indices of CFA in demographic subgroups were concluded in Table 3. According to the fitting indices, the three-factor model fit the data of each sub-sample well, while the twofactor model showed poor fitting degree and was not suitable. In summary, the data fitting performance of the threefactor model was better than that of the two-factor model, whether in the overall sample or in different sociodemographic variable subgroups. Therefore, the three-factor model could be used as the initial model for subsequent tests. 
Table 3

Fitting indices for each model in overall sample and demographic subgroups

\begin{tabular}{|c|c|c|c|c|c|c|c|c|c|}
\hline \multicolumn{2}{|l|}{ Item } & $x^{2}$ & df & p & $\mathrm{CFI}$ & TLI & SRMR & $\begin{array}{l}\text { RMSEA } \\
(90 \% \mathrm{Cl})\end{array}$ & $\mathrm{BIC}$ \\
\hline \multicolumn{10}{|c|}{ Three-factor model } \\
\hline \multicolumn{2}{|l|}{$\begin{array}{l}\text { the overall } \\
\text { sample }\end{array}$} & 345.385 & 51 & $\begin{array}{l}< \\
0.001\end{array}$ & 0.960 & 0.949 & 0.035 & $\begin{array}{l}0.076(0.069 \\
0.084)\end{array}$ & 22690.662 \\
\hline \multirow[t]{2}{*}{ Years of age } & $\leq 45$ & 185.146 & 51 & $<001$ & 0.956 & 0.943 & 0.035 & $\begin{array}{l}0.077(0.065 \\
0.089)\end{array}$ & 10426.611 \\
\hline & $>45$ & 222.719 & 51 & $<.001$ & 0.956 & 0.943 & 0.039 & $\begin{array}{l}0.079 \text { (0.068 } \\
0.089)\end{array}$ & 12372.229 \\
\hline \multirow[t]{2}{*}{$\begin{array}{l}\text { Educational } \\
\text { level }\end{array}$} & $\begin{array}{l}\leq 9 \\
\text { years }\end{array}$ & 215.011 & 51 & $<.001$ & 0.960 & 0.948 & 0.033 & $\begin{array}{l}0.075(0.065 \\
0.086)\end{array}$ & 13087.682 \\
\hline & $\begin{array}{l}>9 \\
\text { years }\end{array}$ & 191.499 & 51 & $<001$ & 0.951 & 0.937 & 0.043 & $\begin{array}{l}0.081(0.065 \\
0.093)\end{array}$ & 9695.626 \\
\hline \multirow[t]{2}{*}{$\begin{array}{l}\text { Place of } \\
\text { residence }\end{array}$} & Urban & 182.325 & 51 & $<0.001$ & 0.963 & 0.953 & 0.039 & $\begin{array}{l}0.069(0.059 \\
0.080)\end{array}$ & 11914.955 \\
\hline & Rural & 232.462 & 51 & $<.001$ & 0.945 & 0.929 & 0.043 & $\begin{array}{l}0.088(0.077 \\
0.100)\end{array}$ & 10792.991 \\
\hline \multicolumn{10}{|l|}{$\begin{array}{l}\text { Two-factor } \\
\text { model }\end{array}$} \\
\hline \multicolumn{2}{|l|}{$\begin{array}{l}\text { the overall } \\
\text { sample }\end{array}$} & 1128.897 & 53 & $\begin{array}{l}< \\
0.001\end{array}$ & 0.856 & 0.820 & 0.086 & $\begin{array}{l}0.143(0.136 \\
0.151)\end{array}$ & 23950.514 \\
\hline \multirow[t]{2}{*}{ Years of age } & $\leq 45$ & $510.867^{\star}$ & 53 & $<.001$ & 0.848 & 0.811 & 0.080 & $\begin{array}{l}0.139(0.128 \\
0.150)\end{array}$ & 10988.712 \\
\hline & $>45$ & $613.437^{*}$ & 53 & $\begin{array}{l}< \\
0.001\end{array}$ & 0.856 & 0.82 & 0.091 & $\begin{array}{l}0.139(0.130 \\
0.149)\end{array}$ & 13065.422 \\
\hline \multirow[t]{2}{*}{$\begin{array}{l}\text { Educational } \\
\text { level }\end{array}$} & $\begin{array}{l}\leq 9 \\
\text { years }\end{array}$ & $633.497 *$ & 53 & $<001$ & 0.858 & 0.823 & 0.079 & $\begin{array}{l}0.139(0.129 \\
0.148)\end{array}$ & 13833.988 \\
\hline & $\begin{array}{l}>9 \\
\text { years }\end{array}$ & $506.132^{\star}$ & 53 & $\begin{array}{l}< \\
0.001\end{array}$ & 0.843 & 0.804 & 0.101 & $\begin{array}{l}0.143(0.132 \\
0.154)\end{array}$ & 10222.138 \\
\hline \multirow[t]{2}{*}{$\begin{array}{l}\text { Place of } \\
\text { residence }\end{array}$} & Urban & $545.386^{\star}$ & 53 & $\begin{array}{l}< \\
0.001\end{array}$ & 0.863 & 0.829 & 0.072 & $\begin{array}{l}0.132(0.122 \\
0.142)\end{array}$ & 12582.588 \\
\hline & Rural & $592.040 *$ & 53 & $\begin{array}{l}<.001 \\
0 .\end{array}$ & 0.838 & 0.798 & 0.103 & $\begin{array}{l}0.150(0.139 \\
0.160)\end{array}$ & 11365.820 \\
\hline
\end{tabular}

As shown in Table 4, the standardized factor loading of each item in the three-factor model of the PSSS was above 0.70 , ranging from 0.794 to 0.967 . The latent correlations between the factors in the total sample were showed in Table 5. All correlations were statistically significant. 
Table 4

Item loadings of three-factor structure in CFA

\begin{tabular}{|llll|}
\hline Item & Standardized factor loadings & \\
\hline 3 & Factor I & Factor II & Factor III \\
\hline 4 & 0.889 & & \\
\hline 8 & 0.904 & & \\
\hline 11 & 0.839 & 0.964 & \\
\hline 6 & 0.857 & 0.967 & \\
\hline 7 & & 0.898 & \\
\hline 9 & & 0.885 & 0.794 \\
\hline 12 & & & 0.867 \\
\hline 1 & & & 0.897 \\
\hline 2 & & & \\
\hline 5 & & & \\
\hline 10 & & & \\
\hline Factor I, family support; Factor II, friends support; Factor III, other support. & \\
\hline
\end{tabular}

Table 5

Correlations between factors in the total sample and sub group

\begin{tabular}{|llll|}
\hline & Factor I & Factor II & Factor III \\
\hline Factor I & 1 & \\
\hline Factor II & $0.681^{\star *}$ & 1 \\
\hline Factor III & $0.695^{\star \star}$ & $0.790^{\star \star}$ & 1 \\
\hline Factor I, family support; Factor II, friends support; Factor III, other support. \\
\hline All correlations with “**” are statistically significant at p 0.01 level.
\end{tabular}

\subsection{Measurement Invariance of PSSS Three-Factor Model Across Demographic Groups}

We evaluated the PSSS measurement invariance across different age groups (under 45 years old and over 45 years old). Configural invariance did not set any parameters to constrain different age groups. All indicators met the fitting requirements, indicating that the scale supported configural invariance. Therefore, this paradigm was used as the baseline model for subsequent nested models. Next, we checked the metric invariance model and set the model parameters so that the factor loading is equal between different age groups. Comparing with the previous model, we could find that $\triangle \mathrm{CFI}$ and $\triangle \mathrm{RMSEA}$ were 0.002 , and $\mathrm{BIC}$ value reduced by 32.103 , which proved that the model supported metric invariance. Consequently, when testing breast cancer patients of different ages, every item of PSSS represented the same meaning. In the next step, the intercept was specified to be equal between the older group and 
the younger group. Compared to the metric invariance model, CFI did not change, RMSEA changed by 0.002 , and BIC decreased by 54.380 , which demonstrated the sufficiency of the scalar invariance. Thus, the strict invariance test could be continued. We limited the error variance to be equal between the older and younger groups. On the basis of the scalar invariance model, CFI changed by 0.002 , RMSEA changed by 0.006 , and BIC decreased by 44.127 . The results confirmed the assumption of strict invariance.

To assess the PSSS measurement invariance in different places of residence, patients were divided into urban and rural groups according to their usual residence. We tested the configuration, metric, scalar, and strict invariance between the two groups in turn. We found that all the invariance models fit the data well. The values of CFI and TLI in each model were greater than 0.9. The values of RMSEA and SRMR were also within a reasonable range. When each model was compared with the previous model, all $\triangle \mathrm{CFI}$ were 0.001 , and the value of BIC were also successively reduced. RMSEA decreased by 0.002 from the configuration invariance model to the metric invariance model, by 0.002 from the metric invariance model to the scalar invariance model, and by 0.005 from the scalar invariance model to the strict invariance model. Therefore, the data satisfied the strict invariance model.

In the end, the measurement invariance of different educational levels was evaluated. According to patients' years of education, women were divided into two groups with lower education level (less than or equal to 9 years) and higher education level (more than 9 years). In each step of the invariance test, all indicators met the model requirements. Comparing each model with the stricter constraint model, $\triangle \mathrm{CFI}$ and $\triangle \mathrm{RMSEA}$ were both less than 0.01 .

Table 6 summarized the fitting indexes of the measurement invariance model under different restricted conditions. In conclusion, it was satisfying that PSSS met the strict invariance model among different ages, education levels and residential groups. 
Table 6

Goodness-of-fit indices and comparison of measurement invariance models

\begin{tabular}{|c|c|c|c|c|c|c|c|c|c|c|}
\hline Item & $x^{2}$ & df & CFI & TLI & SRMR & $\begin{array}{l}\text { RMSEA } \\
(90 \% \mathrm{Cl})\end{array}$ & $\mathrm{BIC}$ & $\Delta \mathrm{CFI}$ & $\triangle \mathrm{RMSEA}$ & $\Delta \mathrm{BIC}$ \\
\hline \multicolumn{11}{|c|}{ Age $(\leq 45$ VS > 45) } \\
\hline $\begin{array}{l}\text { Configural } \\
\text { invariance }\end{array}$ & 408.796 & 102 & 0.956 & 0.943 & 0.037 & $\begin{array}{l}0.078 \\
(0.070- \\
0.086)\end{array}$ & 22853.298 & & & \\
\hline $\begin{array}{l}\text { Metric } \\
\text { invariance }\end{array}$ & 430.557 & 111 & 0.954 & 0.945 & 0.046 & $\begin{array}{l}0.076 \\
(0.069- \\
0.084)\end{array}$ & 22821.195 & 0.002 & 0.002 & 32.103 \\
\hline $\begin{array}{l}\text { Scalar } \\
\text { invariance }\end{array}$ & 440.637 & 120 & 0.954 & 0.949 & 0.046 & $\begin{array}{l}0.074 \\
(0.066- \\
0.081)\end{array}$ & 22766.815 & 0 & 0.002 & 54.380 \\
\hline $\begin{array}{l}\text { strict } \\
\text { invariance }\end{array}$ & 437.022 & 132 & 0.956 & 0.956 & 0.046 & $\begin{array}{l}0.068 \\
(0.061- \\
0.076)\end{array}$ & 22722.688 & 0.002 & 0.006 & 44.127 \\
\hline \multicolumn{11}{|c|}{ Places of residence (Urban VS Rural) } \\
\hline $\begin{array}{l}\text { Configural } \\
\text { invariance }\end{array}$ & 410.838 & 102 & 0.955 & 0.942 & 0.041 & $\begin{array}{l}0.078 \\
(0.070- \\
0.086)\end{array}$ & 22762.261 & & & \\
\hline $\begin{array}{l}\text { Metric } \\
\text { invariance }\end{array}$ & 427.970 & 111 & 0.954 & 0.945 & 0.045 & $\begin{array}{l}0.076 \\
(0.068- \\
0.084)\end{array}$ & 22721.311 & 0.001 & 0.002 & 40.950 \\
\hline $\begin{array}{l}\text { Scalar } \\
\text { invariance }\end{array}$ & 441.343 & 120 & 0.953 & 0.949 & 0.049 & $\begin{array}{l}0.074 \\
(0.066- \\
0.081)\end{array}$ & 22673.980 & 0.001 & 0.002 & 47.331 \\
\hline $\begin{array}{l}\text { strict } \\
\text { invariance }\end{array}$ & 446.247 & 132 & 0.954 & 0.954 & 0.050 & $\begin{array}{l}0.069 \\
(0.062- \\
0.077)\end{array}$ & 22645.505 & 0.001 & 0.005 & 28.475 \\
\hline \multicolumn{11}{|c|}{ Educational level ( $\leq 9$ years VS $>9$ years) } \\
\hline $\begin{array}{l}\text { Configural } \\
\text { invariance }\end{array}$ & 427.481 & 102 & 0.951 & 0.937 & 0.041 & $\begin{array}{l}0.080 \\
(0.073- \\
0.088)\end{array}$ & 22846.538 & & & \\
\hline $\begin{array}{l}\text { Metric } \\
\text { invariance }\end{array}$ & 441.629 & 111 & 0.951 & 0.941 & 0.047 & $\begin{array}{l}0.078 \\
(0.070- \\
0.085)\end{array}$ & 22804.078 & 0.000 & 0.002 & 42.460 \\
\hline $\begin{array}{l}\text { Scalar } \\
\text { invariance }\end{array}$ & 455.898 & 120 & 0.950 & 0.945 & 0.047 & $\begin{array}{l}0.075 \\
(0.068- \\
0.083)\end{array}$ & 22757.927 & 0.001 & 0.003 & 46.151 \\
\hline $\begin{array}{l}\text { strict } \\
\text { invariance }\end{array}$ & 429.604 & 132 & 0.956 & 0.956 & 0.047 & $\begin{array}{l}0.068 \\
(0.060- \\
0.075)\end{array}$ & 22684.405 & 0.006 & 0.007 & 73.522 \\
\hline
\end{tabular}




\section{Discussion}

PSSS is a tool widely used to measure the degree of perceived social support in the general and clinical population. This current study confirmed the construct validity and measurement invariance of the PSSS in a sample of women diagnosed with breast cancer. This investigation contributed to the empirical research of PSSS in some aspects.

First of all, the results of this research verified again the three-factor structure of PSSS, which was consistent with previous findings[7, 40-42]. The study had shown that the three-factor structure of PSSS was better than the twofactor structure in female samples with breast cancer. The three-factor model of PSSS provided an appropriate fit for the overall sample of and the data in each demographic variable group. Based on the above results, the three-factor structure of PSSS can be used as a baseline model for further research on the measurement equivalence of the scale.

In order to determine the measurement invariance of PSSS in the breast cancer population, we established the multigroup models. Four models were evaluated in turn for each demographic statistical variable. Every model had an increasing level of restrictiveness. The results showed that the configural invariance, weak invariance, strong invariance, and strict invariance of PSSS were all supported by the data of breast cancer samples. With the increasing number of equal constraints between groups, the model did not change significantly, and the main psychometric characteristics were not sacrificed. Therefore, the PSSS scale had cross-group stability and was suitable for breast cancer patients with different sociodemographic variables. The establishment of configural invariance indicated that the PSSS measurement of different sociodemographic variable groups can reflect the same number of factors and factor patterns. Moreover, The establishment of weak invariance indicated that the relationship between observed variables and latent variables of PSSS was equivalent among different groups. Every observation item of the scale had the same unit among different groups. Every time the latent variable changes by one unit, the observed variable will have the same degree of change in different groups. The scores of perceived social support between different groups can be directly compared and explained. The same score represented the same meaning. Satisfying strong invariance meant that the cross-group difference in the mean of the observed variable can estimate the difference between the groups in the mean of the latent variable. The comparison of perceived social support among breast cancer patients of different ages, places of residence, and different levels of education was meaningful. Strict invariance showed that the measurement error caused by random factors and the variance of the latent variable were equal among groups. The difference in the scores of the Perceived Social Support Scale at different ages, different levels of education, and different places of residence can be explained by latent variables.

Like other studies, our research had some limitations. We only divided the age stage and education stage into two groups, which can be divided into more detailed groups for further research in the future. Besides, this study is a crosssectional study, without a long-term follow-up survey of patients. Therefore, we cannot evaluate the longitudinal invariance of PSSS over time in breast cancer patients. Further research is needed to determine the characteristics of PSSS scores over time. Finally, PSSS was widely used in clinical practice, yet this study made use of only women with breast cancer as samples. Consequently, the measurement invariance of PSSS under different sociodemographic variables in other clinical patients and healthy people remains to be examined.

In short, we explored the construct validity and psychometric characteristics of PSSS in female breast cancer patients. Despite the above limitations, taking into account the clinical significance, all equivalence models of different degrees can be accepted, and the comparison between different ages, education levels, and residences at the level of the observed variables (total or average score) is meaningful. Therefore, it has good application value in large-scale investigation and research and clinical diagnosis.

Page $12 / 21$ 


\section{Conclusions}

This study provided preliminary evidence for the factor structure and measurement invariance of PSSS across different demographic variables in women diagnosed with breast cancer. Our results proved that PSSS is a threefactor structure scale with good validity and reliability. In addition, the measured invariance results suggest that PSSS can be used in breast cancer patients of different ages, education levels, and places of residence. This property of the scale will ensure the accuracy of results comparison between different groups in future studies.

\section{Abbreviations}

PSSS: Perceived social support scale

CFA: Confirmatory factor analysis

MLMV: Maximum likelihood estimation with standard error and mean-variance corrected chi-square test statistics

CFI: Comparative fit index

TLI: Tucker-Lewis index

BIC: Bayesian information criterion

SRMR: Standardized root mean square residual

RMSEA: Root mean square error of approximation

Cl: Confidence interval

\section{Declarations}

\section{Ethics approval and consent to participate}

The research was approved by the Ethics Committee of Second Xiangya Hospital, Central South University, Changsha, China, and all patients who participated in the study with written informed consent.

\section{Consent for publication}

Written informed consent for publication was obtained from all participants.

\section{Availability of data and materials}

The datasets used and/or analyzed during the current study are available from the corresponding author on reasonable request.

\section{Competing interests}

The authors declare that they have no conflict of interest.

\section{Funding}


This study was funded by National Natural Science Foundation of China (Grant No. 31700962) and the National Key Technologies R\&D program in the 11th 5-year plan from the Ministry of Science and Technology of the People's Republic of China (Grant No. 2009BAI77B06)

\section{Author contributions}

Conceptualization: Yaoxin Chen and Xiongzhao Zhu. Methodology: Yaoxin Chen and Yan Han. Data collection and entry: Yan Han, Huan Zhou, Yao Liu, Lingyan Li and Jie Fan. Data analysis and manuscript preparation: Yaoxin Chen. Review and Amendment: Yaoxin Chen, Xiang Wang, Yuping Wang and Tamini Soondrum. Supervision: Xiongzhao Zhu.

\section{Acknowledgements}

The authors would like to thank all participants for taking the time to complete the survey.

\section{References}

1. Bray F, Ferlay J, Soerjomataram I, et al. Global Cancer Statistics 2018: GLOBOCAN Estimates of Incidence and Mortality Worldwide for 36 Cancers in 185 Countries. CA. Cancer J. Clin. 2018;68(6):394-424.

2. Fan L, Strasser-Weippl K, Li JJ, et al. Breast Cancer in China. Lancet Oncol. 2014;15(7).

3. P. H, G. S, J. M, J. H, J.M. B. The Course of Anxiety and Depression over 5 Years of Follow-up and Risk Factors in Women with Early Breast Cancer: Results from the UK Standardisation of Radiotherapy Trials (START). Breast 2010;19(2):84-91.

4. Sousa Rodrigues Guedes T, Patrocínio da Silva Barros C, Dantas de Oliveira NP, et al. Social Support in the Healthcare of Women Submitted to Breast Cancer Treatment. Women Heal. 2020;60(8):899-911.

5. Blumenthal J A, Burg M M, Barefoot J, Williams R B, Haney T ZG. Social Support, Type A Behavior , and Coronary Artery Disease. Psychosom. Med. 1987;340:331-340.

6. Shao R, He P, Ling B, et al. Prevalence of Depression and Anxiety and Correlations between Depression, Anxiety, Family Functioning, Social Support and Coping Styles among Chinese Medical Students. BMC Psychol. 2020;8(1).

7. Gregory D. Zimet, Suzanne S. Powell, Gordon K. Farley, Sidney Werkman KAB. Psychometric Characteristics of the Multidimensional Scale of Perceived Social Support. J. Pers. Assess. 1990;55(3-4).

8. Chou KL. Assessing Chinese Adolescents' Social Support: The Multidimensional Scale of Perceived Social Support. Pers. Individ. Dif. 2000;28(2):299-307.

9. Denis A, Callahan S, Bouvard M. Evaluation of the French Version of the Multidimensional Scale of Perceived Social Support During the Postpartum Period. Matern. Child Health J. 2015;19(6):1245-1251.

10. Eker D, Arkar H, Yaldiz H. Generality of Support Sources and Psychometric Properties of a Scale of Perceived Social Support in Turkey. Soc. Psychiatry Psychiatr. Epidemiol. 2000;35(5):228-233.

11. Eker D, Arkar H. Perceived Social Support: Psychometric Properties of the MSPSS in Normal and Pathological Groups in a Developing Country. Soc. Psychiatry Psychiatr. Epidemiol. 1995;30(3):121-126.

12. Duru E, Zimet G, Clara IP. Re-Examination of the Psychometric Characteristics of the Multidimensional Scale of Perceived Social Support among Turkish University Students. Soc. Behav. Pers. 2007;35(4):443-452.

13. Başol G. Validity and Reliability of the Multidimensional Scale of Perceived Social Support-Revised, with a Turkish Sample. Soc. Behav. Pers. 2008;36(10):1303-1314. 
14. Martins M V., Peterson BD, Almeida V, Mesquita-Guimarães J, Costa ME. Dyadic Dynamics of Perceived Social Support in Couples Facing Infertility. Hum. Reprod. 2014;29(1):83-89.

15. Martins M V, Peterson BD, Almeida V, Costa ME. Measuring Perceived Social Support in Portuguese Adults Trying to Conceive: Adaptation and Psy- Chometric Evaluation of the Multidimensional Scale of Perceived Social Support. Peritia 2012;13:5-14.

16. López Ramos Y, Fernández Muñoz JJ, Navarro-Pardo E, Murphy M. Confirmatory Factor Analysis for the Multidimensional Scale of Perceived Social Support in a Sample of Early Retirees Enrolled in University Programs. Clin. Gerontol. 2017;40(4):241-248.

17. Cobb CL, Xie D. Structure of the Multidimensional Scale of Perceived Social Support for Undocumented Hispanic Immigrants. Hisp. J. Behav. Sci. 2015;37(2):274-281.

18. Ng CG, Mohamed S, See MH, et al. Anxiety, Depression, Perceived Social Support and Quality of Life in Malaysian Breast Cancer Patients: A 1-Year Prospective Study. Eur. Psychiatry 2016;33(S1):S419-S419.

19. Ghorbani M, Dolatian M, Shams J, Alavi-Majd H. Anxiety, Post-Traumatic Stress Disorder and Social Supports among Parents of Premature and Full-Term Infants. Iran. Red Crescent Med. J. 2014;16(3).

20. Martins M V., Peterson BD, Almeida VM, Costa ME. Direct and Indirect Effects of Perceived Social Support on Womens Infertility-Related Stress. Hum. Reprod. 2011;26(8):2113-2121.

21. Adamczyk K, Segrin C. Direct and Indirect Effects of Young Adults' Relationship Status on Life Satisfaction through Loneliness and Perceived Social Support. Psychol. Belg. 2015;55(4):196-211.

22. Polikandrioti M, Vasilopoulos G, Koutelekos I, et al. Depression in Diabetic Foot Ulcer: Associated Factors and the Impact of Perceived Social Support and Anxiety on Depression. Int. Wound J. 2020;17(4):900-909.

23. Pushkarev GS, Zimet GD, Kuznetsov VA, Yaroslavskaya El. The Multidimensional Scale of Perceived Social Support (MSPSS): Reliability and Validity of Russian Version. Clin. Gerontol. 2020;43(3):331-339.

24. Tsilika E, Galanos A, Polykandriotis T, Parpa E, Mystakidou K. Psychometric Properties of the Multidimensional Scale of Perceived Social Support in Greek Nurses. Can. J. Nurs. Res. 2019;51(1):23-30.

25. Ekbäck M, Benzein E, Lindberg M, Årestedt K. The Swedish Version of the Multidimensional Scale of Perceived Social Support (MSPSS) - a Psychometric Evaluation Study in Women with Hirsutism and Nursing Students. Health Qual. Life Outcomes 2013;11(1).

26. Tonsing K, Zimet GD, Tse S. Assessing Social Support among South Asians: The Multidimensional Scale of Perceived Social Support. Asian J. Psychiatr. 2012;5(2):163-167.

27. Lee MK, Park S, Lee ES, et al. Social Support and Depressive Mood 1 Year after Diagnosis of Breast Cancer Compared with the General Female Population: A Prospective Cohort Study. Support. Care Cancer 2011;19(9):1379-1392.

28. Bener A, Alsulaiman R, Doodson L, Agathangelou T. Depression, Hopelessness and Social Support among Breast Cancer Patients: In Highly Endogamous Population. Asian Pacific J. Cancer Prev. 2017;18(7):1889-1896.

29. Ji L li, Tsai W, Sun X lian, et al. The Detrimental Effects of Ambivalence over Emotional Expression on Well-Being among Mainland Chinese Breast Cancer Patients: Mediating Role of Perceived Social Support. Psychooncology. 2019;28(5):1142-1148.

30. Kim J, Jang M. Stress, Social Support, and Sexual Adjustment in Married Female Patients with Breast Cancer in Korea. Asia-Pacific J. Oncol. Nurs. 2019:28-35.

31. Sammarco A. Quality of Life of Breast Cancer Survivors: A Comparative Study of Age Cohorts. Cancer Nurs. 2009;32(5):347-356. 
32. Yang L, Song WP, Chen ZL, et al. Correlation between Social Support and Quality of Life in Patients with Breast Cancer at Different Periods of Treatment. Zhonghua Zhong Liu Za Zhi 2017;39(3):202-206.

33. Muthén LK, Muthén BO. Mplus: Statistical Analysis with Latent Variables: User's Guide; 2012; Vol. 7th.

34. Flora DB, Curran PJ. An Empirical Evaluation of Alternative Methods of Estimation for Confirmatory Factor Analysis with Ordinal Data. Psychol. Methods 2004;9(4):466-491.

35. Cheung GW, Rensvold RB. Evaluating Goodness-of-Fit Indexes for Testing Measurement Invariance. Struct. Equ. Model. 2002;9(2):233-255.

36. Hu LT, Bentler PM. Cutoff Criteria for Fit Indexes in Covariance Structure Analysis: Conventional Criteria versus New Alternatives. Struct. Equ. Model. 1999;6(1):1-55.

37. Meredith W. Measurement Invariance,Factor-Analysis and Factorial Invariance. Psychometrika 1993;58(4):525543.

38. Abubakar A, van de Vijver F, Alonso-Arbiol I, et al. Measurement Invariance of the Brief Multidimensional Student's Life Satisfaction Scale Among Adolescents and Emerging Adults Across 23 Cultural Contexts. J. Psychoeduc. Assess. 2016;34(1):28-38.

39. Zeng Y, Ling Y, Huebner ES, He Y, Fu P. Assessing the Measurement Invariance of the Brief Multidimensional Students' Life Satisfaction Scale in Chinese and American Adolescents. Qual. Life Res. 2018;27(1):259-266.

40. Nearchou F, Davies A, Hennessy E. Psychometric Evaluation of the Multi-Dimensional Scale of Perceived Social Support in Young Adults with Chronic Health Conditions. Ir. J. Psychol. Med. 2019:1-5.

41. Cartwright A V., Pione RD, Stoner CR, Spector A. Validation of the Multidimensional Scale of Perceived Social Support (MSPSS) for Family Caregivers of People with Dementia. Aging Ment. Heal. 2020.

42. Teh WL, Shahwan S, Abdin E, et al. Confirmatory Factor Analysis and Measurement Invariance of the Multidimensional Scale of Perceived Social Support in Young Psychiatric and Non-Psychiatric Asians. Ann. Acad. Med. Singapore 2019;48(10):314-320.

\section{Tables}

Table 1 Demographic and disease related information of the patients 


\begin{tabular}{|c|c|}
\hline Item & N (\%) \\
\hline \multicolumn{2}{|l|}{ Years of age } \\
\hline$\leq 45$ & 445 (45.0\%) \\
\hline$>45$ & 544 (55.0\%) \\
\hline \multicolumn{2}{|l|}{ Marital status } \\
\hline Married & 925 (93.5\%) \\
\hline Divorced & 33 (3.3\%) \\
\hline Widowed & $28(2.8 \%)$ \\
\hline Single & $3(0.3 \%)$ \\
\hline \multicolumn{2}{|l|}{ Educational level } \\
\hline$\leq 9$ years & 570 (57.6\%) \\
\hline$>9$ years & $419(42.4 \%)$ \\
\hline \multicolumn{2}{|l|}{ Place of residence } \\
\hline Urban & $534(54.0 \%)$ \\
\hline Rural & $455(46.0 \%)$ \\
\hline \multicolumn{2}{|l|}{ Stage of disease } \\
\hline Preoperative & 233 (23.5\%) \\
\hline Postoperative & 701 (70.9\%) \\
\hline Convalescent & 55 (5.6\%) \\
\hline
\end{tabular}

Table 2 Descriptive data on items scores. 


\begin{tabular}{ccccc}
\hline Item & Mean & SD & Skewness & Kurtosis \\
\hline 1 & 5.73 & 0.956 & -1.115 & 2.104 \\
2 & 5.42 & 1.074 & -0.845 & .803 \\
3 & 6.25 & 0.756 & -1.278 & 3.891 \\
4 & 6.21 & 0.823 & -1.237 & 2.859 \\
5 & 5.19 & 1.158 & -0.459 & -0.243 \\
6 & 5.17 & 1.253 & -0.685 & 0.262 \\
7 & 5.12 & 1.321 & -0.663 & 0.113 \\
8 & 5.95 & 0.939 & -0.953 & 1.363 \\
9 & 5.25 & 1.273 & -0.841 & 0.482 \\
10 & 5.45 & 1.034 & -0.595 & 0.472 \\
11 & 6.23 & 0.779 & -1.027 & 1.742 \\
12 & 5.28 & 1.346 & -0.852 & 0.305 \\
\hline
\end{tabular}

Table 3 Fitting indices for each model in overall sample and demographic subgroups 


\begin{tabular}{|c|c|c|c|c|c|c|c|c|c|}
\hline Item & & $\chi^{2}$ & $\mathrm{df}$ & $\mathrm{p}$ & CFI & TLI & SRMR & RMSEA (90\%CI) & BIC \\
\hline \multicolumn{10}{|l|}{ Three-factor model } \\
\hline the overall sample & & 345.385 & 51 & $<0.001$ & 0.960 & 0.949 & 0.035 & $0.076(0.0690 .084)$ & 22690.662 \\
\hline \multirow[t]{2}{*}{ Years of age } & $\leq 45$ & 185.146 & 51 & $<0.001$ & 0.956 & 0.943 & 0.035 & $0.077(0.0650 .089)$ & 10426.611 \\
\hline & $>45$ & 222.719 & 51 & $<0.001$ & 0.956 & 0.943 & 0.039 & $0.079(0.0680 .089)$ & 12372.229 \\
\hline \multirow[t]{2}{*}{ Educational level } & $\leq 9$ years & 215.011 & 51 & $<0.001$ & 0.960 & 0.948 & 0.033 & $0.075(0.0650 .086)$ & 13087.682 \\
\hline & $>9$ years & 191.499 & 51 & $<0.001$ & 0.951 & 0.937 & 0.043 & $0.081(0.0650 .093)$ & 9695.626 \\
\hline \multirow[t]{2}{*}{ Place of residence } & Urban & 182.325 & 51 & $<0.001$ & 0.963 & 0.953 & 0.039 & $0.069(0.0590 .080)$ & 11914.955 \\
\hline & Rural & 232.462 & 51 & $<0.001$ & 0.945 & 0.929 & 0.043 & $0.088(0.0770 .100)$ & 10792.991 \\
\hline \multicolumn{10}{|l|}{ Two-factor model } \\
\hline the overall sample & & 1128.897 & 53 & $<0.001$ & 0.856 & 0.820 & 0.086 & $0.143(0.1360 .151)$ & 23950.514 \\
\hline \multirow[t]{2}{*}{ Years of age } & $\leq 45$ & $510.867 *$ & 53 & $<0.001$ & 0.848 & 0.811 & 0.080 & $0.139(0.1280 .150)$ & 10988.712 \\
\hline & $>45$ & $613.437 *$ & 53 & $<0.001$ & 0.856 & 0.82 & 0.091 & $0.139(0.1300 .149)$ & 13065.422 \\
\hline \multirow[t]{2}{*}{ Educational level } & $\leq 9$ years & $633.497 *$ & 53 & $<0.001$ & 0.858 & 0.823 & 0.079 & $0.139(0.1290 .148)$ & 13833.988 \\
\hline & $>9$ years & $506.132 *$ & 53 & $<0.001$ & 0.843 & 0.804 & 0.101 & $0.143(0.1320 .154)$ & 10222.138 \\
\hline \multirow[t]{2}{*}{ Place of residence } & Urban & $545.386 *$ & 53 & $<0.001$ & 0.863 & 0.829 & 0.072 & $0.132(0.1220 .142)$ & 12582.588 \\
\hline & Rural & $592.040 *$ & 53 & $<0.001$ & 0.838 & 0.798 & 0.103 & $0.150(0.1390 .160)$ & 11365.820 \\
\hline
\end{tabular}

$\chi^{2}$, chi-square; df, degrees of freedom; CFI, comparative fit index; TLI, Tucker-Lewis index; SRMR, standardized root mean square residual; RMSEA, root mean square error of approximation; CI, confidence interval; BIC, Bayesian information criterion.

Table 4 Item loadings of three-factor structure in CFA 


\begin{tabular}{|c|c|c|c|}
\hline \multirow[t]{2}{*}{ Item } & \multicolumn{3}{|c|}{ Standardized factor loadings } \\
\hline & Factor I & Factor II & Factor III \\
\hline 3 & 0.889 & & \\
\hline 4 & 0.904 & & \\
\hline 8 & 0.839 & & \\
\hline 11 & 0.857 & & \\
\hline 6 & & 0.964 & \\
\hline 7 & & 0.967 & \\
\hline 9 & & 0.898 & \\
\hline 12 & & 0.885 & \\
\hline 1 & & & 0.794 \\
\hline 2 & & & 0.851 \\
\hline 5 & & & 0.867 \\
\hline 10 & & & 0.897 \\
\hline
\end{tabular}

Factor I, family support; Factor II, friends support; Factor III, other support.

Table 5 Correlations between factors in the total sample and sub group

\begin{tabular}{cccc}
\hline & Factor I & Factor II & Factor III \\
\hline Factor I & 1 & & \\
Factor II & $0.681^{* *}$ & 1 & \\
Factor III & $0.695^{* *}$ & $0.790^{* *}$ & 1 \\
\hline
\end{tabular}

Factor I, family support; Factor II, friends support; Factor III, other support. All correlations with “**” are statistically significant at p 0.01 level. 
Table 6 Goodness-of-fit indices and comparison of measurement invariance models

\begin{tabular}{|c|c|c|c|c|c|c|c|c|c|c|}
\hline Item & $\chi^{2}$ & $\mathrm{df}$ & CFI & TLI & SRMR & RMSEA (90\%CI) & BIC & $\Delta \mathrm{CFI}$ & $\triangle$ RMSEA & $\Delta \mathrm{BIC}$ \\
\hline \multicolumn{11}{|l|}{ Age $(\leq 45$ VS $>45)$} \\
\hline Configural invariance & 408.796 & 102 & 0.956 & 0.943 & 0.037 & $0.078(0.070-0.086)$ & 22853.298 & & & \\
\hline Metric invariance & 430.557 & 111 & 0.954 & 0.945 & 0.046 & $0.076(0.069-0.084)$ & 22821.195 & 0.002 & 0.002 & 32.103 \\
\hline Scalar invariance & 440.637 & 120 & 0.954 & 0.949 & 0.046 & $0.074(0.066-0.081)$ & 22766.815 & 0 & 0.002 & 54.380 \\
\hline strict invariance & 437.022 & 132 & 0.956 & 0.956 & 0.046 & $0.068(0.061-0.076)$ & 22722.688 & 0.002 & 0.006 & 44.127 \\
\hline \multicolumn{11}{|c|}{ Places of residence (Urban VS Rural) } \\
\hline Configural invariance & 410.838 & 102 & 0.955 & 0.942 & 0.041 & $0.078(0.070-0.086)$ & 22762.261 & & & \\
\hline Metric invariance & 427.970 & 111 & 0.954 & 0.945 & 0.045 & $0.076(0.068-0.084)$ & 22721.311 & 0.001 & 0.002 & 40.950 \\
\hline Scalar invariance & 441.343 & 120 & 0.953 & 0.949 & 0.049 & $0.074(0.066-0.081)$ & 22673.980 & 0.001 & 0.002 & 47.331 \\
\hline strict invariance & 446.247 & 132 & 0.954 & 0.954 & 0.050 & $0.069(0.062-0.077)$ & 22645.505 & 0.001 & 0.005 & 28.475 \\
\hline \multicolumn{11}{|c|}{ Educational level ( $\leq 9$ years VS $>9$ years) } \\
\hline Configural invariance & 427.481 & 102 & 0.951 & 0.937 & 0.041 & $0.080(0.073-0.088)$ & 22846.538 & & & \\
\hline Metric invariance & 441.629 & 111 & 0.951 & 0.941 & 0.047 & $0.078(0.070-0.085)$ & 22804.078 & 0.000 & 0.002 & 42.460 \\
\hline Scalar invariance & 455.898 & 120 & 0.950 & 0.945 & 0.047 & $0.075(0.068-0.083)$ & 22757.927 & 0.001 & 0.003 & 46.151 \\
\hline strict invariance & 429.604 & 132 & 0.956 & 0.956 & 0.047 & $0.068(0.060-0.075)$ & 22684.405 & 0.006 & 0.007 & 73.522 \\
\hline
\end{tabular}

$\chi^{2}$, chi-square; df, degrees of freedom; CFI, comparative fit index; TLI, Tucker-Lewis index; SRMR, standardized root mean square residual; RMSEA, root mean square error of approximation; CI, confidence interval; BIC, Bayesian information criterion; $\Delta$, change in the parameter. 